\title{
What shapes physical activity attitudes within an ethnic minority? An intergenerational comparison of British Indian women
}

Prachi Bhatnagar ( $\nabla$ prachi.bhatnagar@dph.ox.ac.uk)

University of Oxford https://orcid.org/0000-0002-5231-9625

Charlie Foster

University of Bristol

Alison Shaw

University of Oxford

Research article

Keywords: ethnicity; qualitative; inter-generational; South Asian; women

Posted Date: September 5th, 2019

DOl: https://doi.org/10.21203/rs.2.13912/v1

License: (c) (i) This work is licensed under a Creative Commons Attribution 4.0 International License.

Read Full License 


\section{Abstract}

Background: Survey data indicate that second-generation UK South Asian women are more physically active than first-generation women, but less active than White British women. In the 2011 UK census, approximately $50 \%$ of UK South Asian ethnic groups were born in the UK, and this group is increasing as the second-generation also have children. Qualitative work is needed to determine why these changes in physical activity have occurred and how we might further reduce the gap in physical activity levels between White British women and British Indian women. Methods: We used qualitative methods to understand attitudes, barriers and motivations for physical activity in two generations of British Indian women, using a socioecological model to take into account the wider social and physical contexts. We conducted semi-structured interviews with 28 Indian women living in Manchester, England. Respondents completed a 7-day exercise diary prior to the interview. Interviews were audio-recorded, transcribed, thematically coded and analysed using a grounded theory approach. Results : Gender strongly influenced the physical activity of both the first and second-generation. Physical activity lessons in school and the media influenced second-generation Indian women's attitudes to physical activity. Consequently, their motivations and barriers to physical activity were very similar to those reported for White British women. Second-generation Muslim women reported their religion affecting the way they exercise, however this was not the case for the Hindu and Sikh women in this study. First-generation Indian women reported prioritising family and housework over leisure-time physical activity; this is similar to findings reported in previous research on physical activity in South Asian women. Conclusions : Among second-generation Indian women, gender-related barriers to physical activity were very similar to those already reported for White British women. Therefore public health measures aimed at combating conflicts between femininity and being physically active may also positively affect second-generation Indian women. First-generation Indian women are likely to respond better to culturally tailored interventions. Future research should further explore the effects of religion on the physical activity on women and generational differences in the physical activity attitudes of other ethnic minorities.

\section{Background}

Physical inactivity is linked with all-cause mortality and most studies demonstrate that higher physical activity and fitness levels lower the risk of dying at a younger age ${ }^{1}$. Physical inactivity is prevalent among South Asian women worldwide, including in the UK, particularly with regards to leisure-time physical activity ${ }^{2,3}$.

In England, physical activity levels among South Asians are approximately $60 \%$ lower than among White British, and lowest in South Asian women ${ }^{4}$; however little attention has been paid to variation in physical activity levels within South Asian ethnic groups. This is vital as there are generational differences in the physical activity of UK South Asians: the UK-born generation is more physically active than the migrantorigin first-generation, but less active than the White British population ${ }^{5}$. At present, we do not have the necessary knowledge to reduce this gap in physical activity between second-generation Indian women 
and White British women because most research in this area has been conducted with older, firstgeneration women who migrated to the UK in the mid-twentieth century ${ }^{5}$. The most recent UK census showed that $50 \%$ of UK South Asians were born in the UK ${ }^{6}$. Consequently, the existing research on motivations and barriers to physical activity among British South Asians may not reflect the experiences of about half of the UK South Asian population. As the second-generation of ethnic minority women also have children, the UK-born group are increasing. Existing research on the motivators and barriers to physical activity among UK South Asian women has mainly reported on cultural barriers ${ }^{3}$; these include women prioritising family commitments over their own health or physical activity and considering physical activity to be unimportant.

Intergenerational differences in physical activity may be due to differences in age, socioeconomic status, changes in the physical and social environment, or acculturation to the norms and values of mainstream society 7,8 . Research on acculturation and health has lacked an explicit or current theoretical base or used proxy measures that do not capture people's values and attitudes ${ }^{9}$. Much research on acculturation within public health uses simple descriptive proxy measures such as place of birth, language use or generational status, which do not reflect people's underlying attitudes or beliefs ${ }^{10}$. The Indian cultural system can described as collectivist and family orientated, in contrast to the individualistic British or Western cultural system ${ }^{11-13}$. In a collectivistic culture, a person defines themselves in terms of their role within society, rather than as a person separate from society ${ }^{11}$. This sheds light on findings on attitudes to physical activity among South Asian women, where women prioritise the family over themselves ${ }^{3}$. Second-generation Indian women have grown up in both Western and Indian cultural systems and therefore may be influenced by an individualistic culture. However, to date the role of individualistic versus collectivist notions of personhood in relation to gender and physical activity has not been explored in health research with UK ethnic minorities.

Very little is also known about how physical and social environments, which are known to be important determinants of physical activity, may have influenced intergenerational changes in physical activity among South Asian women. The UK, India and East African countries differ vastly in terms of their leisure facilities, school curriculums, walkable infrastructure, transport infrastructure and weather, and yet we know almost nothing about how these different environments may have influenced changes in attitudes to physical activity among first and second generation UK South Asians.

We focused our study on women of Indian ethnicity. We aimed to understand how attitudes to physical activity might differ between two generations of Indian women living in the UK, using the socio-ecological model a basis for understanding the range of influences on physical activity.

\section{Theoretical Framework}

Two theoretical frameworks informed this study: a socioecological model for physical activity ${ }^{14}$ and intersectionality theory ${ }^{15}$. The socio-ecological model for physical activity proposes that policy; physical and social environments; and individual factors such as age and sex influence physical activity ${ }^{14}$. These 
elements interact with each other, in ways that differ between populations. The value of this multi-level model of influences on physical activity in ethnic groups is that it helps contextualise behaviour and reminds us that ethnic minority women often inhabit the same physical and social environments as the majority population. Intersectionality theory complements the socioecological model through stressing how multiple social positions - such as ethnicity, gender, class or sexuality - interact to influence lived experiences $^{15}$. This has also been extended to exploring the intersection of influences on health, acknowledging that micro, meso and macro societal factors combine in different way to influence the health outcomes of different social groups ${ }^{16}$.

\section{Methods}

\section{Study Design}

We conducted semi-structured interviews with 28 British Indian women, 19 of whom were secondgeneration. We defined the second-generation as those who were born in the United Kingdom (UK) or moved to the UK before age 11, which coincides with the start of secondary-schooling in the UK and has previously been used in research exploring generational differences in UK South Asians ${ }^{17}$. Participants were invited to complete a 7-day exercise diary and a semi-structured, audio-recorded interview. We used modified grounded theory methods to code the interview transcripts and explore emergent themes.

\section{Data Collection}

We used a socio-ecological model to help develop the interview guide (Table 1) to ensure we explored questions beyond the influence of ethnicity on physical activity. Questions were open-ended, based on the topics listed in the interview guide. During the interviews, participants were given a map of their local area to prompt discussions about how they use their neighbourhood for physical activity. Throughout the data collection process, the interviewer kept a field diary for noting immediate thoughts and summarising interviews. All interviews were conducted in English, although the interviewer understands Hindi.

Recruitment used a variety of strategies devised after reviewing literature on recruiting minority groups into health research. We recruited people into the study by advertising in public spaces, email lists, approaching local community organisations, through primary schools and nurseries, and using snowballing techniques.

\section{Table 1 Topics included in interview guide}




\begin{tabular}{|c|c|c|}
\hline Overall theme/main question & Sub-theme & Further breakdown of sub-theme \\
\hline \multicolumn{3}{|l|}{$\begin{array}{l}\text { Explanation that our discussion will be } \\
\text { partly based on the physical activity diary } \\
\text { filled in. }\end{array}$} \\
\hline \multicolumn{3}{|l|}{$\begin{array}{l}\text { Clarification will be talking about the } \\
\text { activity do during your free- time, while } \\
\text { walking, and while in the home. }\end{array}$} \\
\hline \multicolumn{3}{|l|}{ How active would you say you are? } \\
\hline \multirow[t]{4}{*}{ Individual influences on physical activity } & Ethnicity & $\begin{array}{ll}\cdot & \text { Parental attitudes } \\
. & \text { Parental behaviour } \\
. & \text { Wider family attitudes } \\
. & \text { Others in ethnic group } \\
. & \text { Religion } \\
\end{array}$ \\
\hline & Gender & \\
\hline & Age group & \\
\hline & $\begin{array}{l}\text { Personal } \\
\text { interests }\end{array}$ & \\
\hline \multirow[t]{3}{*}{ Social environment's influence on activity } & Media & \\
\hline & Colleagues & \\
\hline & Friends & \\
\hline \multirow[t]{4}{*}{$\begin{array}{l}\text { Physical environment's influence on } \\
\text { activity }\end{array}$} & $\begin{array}{l}\text { Local } \\
\text { neighbourhood }\end{array}$ & \\
\hline & $\begin{array}{l}\text { Area around } \\
\text { work }\end{array}$ & \\
\hline & $\begin{array}{l}\text { Climate and } \\
\text { weather }\end{array}$ & \\
\hline & $\begin{array}{l}\text { Drawing of } \\
\text { neighbourhood } \\
\text { map }\end{array}$ & $\begin{array}{l}\text { Would you mind marking out on this map where your } \\
\text { neighbourhood is? There is no right or wrong answer, I'm just } \\
\text { looking to see which areas we have been discussing. }\end{array}$ \\
\hline \multicolumn{3}{|l|}{ Exercise now and in childhood } \\
\hline \multicolumn{3}{|l|}{ How important do you think exercise is? } \\
\hline Any questions for the interviewer & & \\
\hline
\end{tabular}

\section{Participants}

This study was based in Greater Manchester, United Kingdom. We interviewed participants in locations spanning some of the most and least deprived areas in Greater Manchester. Area deprivation was measured using the Index of Multiple Deprivation ${ }^{18}$. We purposively sampled participants at different life stages and with varying occupations (Table 2). Participants had to be resident in Manchester/Greater Manchester, to identify as having Indian ethnicity and be at least 18 years old. Interviews were held in a location chosen by the participant.

Table 2 Characteristics of first and second-generation participants 


\begin{tabular}{|c|c|c|c|}
\hline & & Second-generation $(\mathrm{N}=19)$ & First-generation $(\mathrm{N}=9)$ \\
\hline \multirow[t]{5}{*}{ Age group } & 20 to 29 & 9 & 0 \\
\hline & 30 to 39 & 6 & 1 \\
\hline & 40 to 49 & 3 & 0 \\
\hline & 50 to 59 & 1 & 6 \\
\hline & 60 to 69 & 0 & 2 \\
\hline \multirow[t]{4}{*}{ Religion } & Hindu & 14 & 7 \\
\hline & Sikh & 2 & 0 \\
\hline & Jain & 1 & 2 \\
\hline & Muslim & 2 & 0 \\
\hline \multirow{2}{*}{$\begin{array}{l}\text { Family/personal } \\
\text { migration } \\
\text { history }\end{array}$} & East Africa & 6 & 4 \\
\hline & India & 13 & 5 \\
\hline \multirow{5}{*}{$\begin{array}{l}\text { Index of Multiple } \\
\text { Deprivation } \\
\text { quintile }\end{array}$} & 1 (most deprived) & 6 & 1 \\
\hline & 2 & 6 & 2 \\
\hline & 3 & 2 & 1 \\
\hline & 4 & 1 & 0 \\
\hline & 5 (least deprived) & 4 & 5 \\
\hline \multirow{17}{*}{$\begin{array}{l}\text { Occupations as } \\
\text { described by } \\
\text { participants }\end{array}$} & Account manager, advertising & 1 & 0 \\
\hline & Administrator & 0 & 1 \\
\hline & Bank Clerk & 1 & 0 \\
\hline & Bank Portfolio Manager & 1 & 0 \\
\hline & Clerical Officer & 1 & 0 \\
\hline & Customer Services & 1 & 1 \\
\hline & Dentist & 1 & 0 \\
\hline & Doctor & 1 & 2 \\
\hline & General assistant & 0 & 1 \\
\hline & Retired bakery worker & 0 & 1 \\
\hline & Software consultant & 0 & 1 \\
\hline & Student & 7 & 0 \\
\hline & Systems developer & 0 & 1 \\
\hline & Teaching Assistant & 2 & 1 \\
\hline & Trainee Solicitor & 1 & 0 \\
\hline & Volunteer & 1 & 0 \\
\hline & Works in family business & 1 & 0 \\
\hline
\end{tabular}

\section{Analysis}

We analysed each interview as soon as it was transcribed, and continued to recruit participants until no new themes were emerging in the data. First and second-generation interviews were analysed separately. Initially, interviews were coded using words or short phrases to summarise extracts. Constant comparative methods were used to explore similarities and differences between interviews. We then identified codes that were common across interviews and sorted them according to whether they related to a barrier, an influence, a stage of life, or categories of people such as parents or friends. PB reviewed all transcripts to ensure the initial codes used were appropriate and to check if any implicit or vaguely-stated 
concepts had been missed. Finally, we used theoretical codes to look for relationships and connections between codes and groups of codes. PB used memos to record insights into the codes and used these, along with the codes themselves, to develop understanding of their influences on physical activity. Once themes had emerged from the transcripts, themes in the first and second-generation interviews were compared, using the socio-ecological model used as a general guide to group these themes.

\section{Results}

Six major themes emerged in the data: gender; religion; ageing and family illness; schooling; the media, and the neighbourhood as barriers to and/or motivators for physical activity (table 3 ). Here, we summarise these themes with illustrative quotes, highlighting generational where these emerged.

Table 3 Emergent themes with illustrative quotes 


\begin{tabular}{|c|c|c|}
\hline Theme & Sub theme & Illustrative quote \\
\hline \multirow[t]{5}{*}{ Gender } & $\begin{array}{l}\text { Ways of } \\
\text { socialising }\end{array}$ & $\begin{array}{l}\text { Yeah, it's not just exercise, it's stuff like, you know, playing football 'cos there's so many similar } \\
\text { guys who have got similar ages in Manchester so that's how they socialise, they just play } \\
\text { football in the park. Whereas with girls it's not like there's an easy way to play a sport together } \\
\text { (Participant 1, Second-generation, Trainee solicitor). }\end{array}$ \\
\hline & $\begin{array}{l}\text { Physical } \\
\text { appearance }\end{array}$ & $\begin{array}{l}\text { When I used to go to the gym quite a lot last year we used to go to like the weights because } \\
\text { obviously not a lot of women do, but it's actually the quickest way to lose weight in fact, so we } \\
\text { used to go and we just used to get stared at...it just wasn't a nice experience, so like you } \\
\text { always had to go somewhere else and maybe not do weights when other people are there. } \\
\text { (Participant 2, second-generation, age 22, Medical student) } \\
\text { I think ladies over here ... English born-brought up, they are quite into it ... I'm talking about } \\
\text { British - they are quite active... totally into exercising, but then their culture is totally different. } \\
\text {.... They come back home and again go for a run - [exclaims] aii - we don't do all those things, } \\
\text { we don't make that effort to maintain ourselves. I think they have activity in the culture because } \\
\text { they want to look good in pubs and they have all this culture isn't it? Going for holidays to Spain, } \\
\text { they have to look glamorous. We're not bothered, we don't bother about our looks - once we get } \\
\text { married, I don't think so anybody is bothered about our looks. And they say that openly as well. } \\
\text { Abhi kya karna abhi? [What do you need to do now?] So you think this is not important, and } \\
\text { anyway if I maintain myself there's no point. It's my husband who will be looking at me, so it's } \\
\text { ok [laughs] (Participant 9, First-generation, Software consultant). }\end{array}$ \\
\hline & $\begin{array}{l}\text { Time for } \\
\text { oneself }\end{array}$ & $\begin{array}{l}\text { I used to go there a few years ago and then stopped for a while, and then started back again } \\
\text { [because] I think it's more doing something for myself, having time for myself to do something, } \\
\text { because I don't really do anything out on a regular basis. Like my husband goes to the gym, my } \\
\text { kids go to the gym but I don't do anything so that was just something for me... It gets me out } \\
\text { with my friends as well, and I think we all enjoy it. Because we all go together, we all car-share, } \\
\text { it's just fun (Participant 14, Second-generation, Bank clerk). }\end{array}$ \\
\hline & $\begin{array}{l}\text { Safety } \\
\text { concerns }\end{array}$ & $\begin{array}{l}\text {... I do more walking here [at university] 'cos when I was at home, and because you're younger, } \\
\text { then ... my parents would never really send me out to walk anywhere really. When I was in year } \\
7 \text {, or year } 6 \text { age, I did Brownies and ... the place I did it was only like a } 10 \text { minute walk away, but } \\
\text { they'd never feel comfortable sending me out by myself, so they'd drive me everywhere really } \\
\text { (Participant 3, Second-generation, Medical student). } \\
\text { Compared to my male cousins, when I was growing up - there are like one or two who are older } \\
\text { than me - I think they were allowed to like, go on the road and ride the bike and stuff like that, } \\
\text { but we weren't allowed to go and I knew that was because I was a girl so I think, but I didn't } \\
\text { stop me from - I don't know how to describe it but I didn't feel it was a bad thing that they were } \\
\text { not letting us go cos I just thought like because they wanted me to be safe. (Participant 1, } \\
\text { second-generation, Trainee solicitor) }\end{array}$ \\
\hline & $\begin{array}{l}\text { Domestic } \\
\text { activity and } \\
\text { family } \\
\text { priorities }\end{array}$ & $\begin{array}{l}\text { "[In the]...morning when my daughter would [wakes up], even having a baby just now - very } \\
\text { young baby - first thing she'll ask me, 'mummy is it ok if I go on the treadmill?' At the time } \\
\text { when I would be doing my exercise when I say exercise - the work in the kitchen - getting the } \\
\text { dough ready which my muscles are working making the dough while her priority is, 'every day I } \\
\text { have to go on treadmill'..." (Participant 24, First-generation, Doctor) } \\
\text { I think our generation - I think we still worry about it less, I think, I think for us because we } \\
\text { don't really think about maybe the extended family, it's only just [us] and our husband and then } \\
\text { our children. We don't have to take care of all the others, and then usually our husbands are } \\
\text { quite independent as well, so I think we haven't got that burden on us that much, so we can } \\
\text { focus on us. (Participant } 20 \text {, second-generation, Works in family business) }\end{array}$ \\
\hline
\end{tabular}

Page 8/17 


\begin{tabular}{|c|c|c|}
\hline Religion & & $\begin{array}{l}\text { - Islam would say go to a ladies' gym. You can go to the gym, there's no harm in it, but go to the } \\
\text { ladies' gym. Islam doesn't like it when you mix with other men - do you get it? (Participant 19, } \\
\text { Second-generation, Teaching assistant). }\end{array}$ \\
\hline $\begin{array}{l}\text { Ageing and } \\
\text { Illness }\end{array}$ & & $\begin{array}{l}\text {... with my dad being on the borderline [of diabetes] and then because you know that it's got like } \\
\text { genetic links and I know that my dad's dad didn't have that, but all of my dad's mums side, like } \\
\text { they all had it, or if it wasn't diabetes then they had a heart attack, so it's all like, you don't want } \\
\text { to get things like that (Participant } 4 \text {, Second-generation, Medical student). }\end{array}$ \\
\hline \multirow[t]{2}{*}{ Schooling } & $\begin{array}{l}\text { Physical } \\
\text { education } \\
\text { (PE) lessons }\end{array}$ & $\begin{array}{l}\text { I think like, we've like learnt from school recently, like everyone was pushed to exercise and like } \\
\text { the Olympics and everything - the health benefits, but I don't know if she thinks it's that } \\
\text { important. I think we've learnt through school and stuff - we've been told how important } \\
\text { exercise is and to have an active lifestyle is good for your health, but I don't know if she's had - } \\
\text { I don't think she realises that it's probably good for her to do more exercise (Participant 7, } \\
\text { Second-generation, Mathematics student). }\end{array}$ \\
\hline & $\begin{array}{l}\text { Education as } \\
\text { a barrier to } \\
\text { physical } \\
\text { activity in } \\
\text { adolescence }\end{array}$ & $\begin{array}{l}\text {... You're going to get more in life by studying than going to the gym or playing sports, so } \\
\text { (laughs). That's the way it was when I was growing up to be honest (Participant 6, Second- } \\
\text { generation, Dentist). }\end{array}$ \\
\hline The media & & $\begin{array}{l}\text { My dad watches Indian channels, which is where I could see it, but as I say, those channels } \\
\text { come from India and they don't really push health as much as we do here. It never really comes } \\
\text { up, like the people on the screen will be thin but it's not pushed. Like if you pick up a magazine } \\
\text { here it's like, lose this many pounds in a week (Participant 4, Second-generation, Medical } \\
\text { student). }\end{array}$ \\
\hline $\begin{array}{l}\text { The } \\
\text { neighbourhood }\end{array}$ & $\begin{array}{l}\text { Local } \\
\text { facilities for } \\
\text { physical } \\
\text { activity }\end{array}$ & $\begin{array}{l}\text { PB: Why don't you go to the park? } \\
\text { When children were young that time I used to go play with children, they liked to go park, very } \\
\text { young children, that time I used to go there. That place swinging and just running round with the } \\
\text { park, everything, they like. When they were young children I used to go, but now I don't go park. } \\
\text { (Participant 12, First-generation, Supermarket General Assistant). }\end{array}$ \\
\hline
\end{tabular}

\section{Gender}

The impact of being female on physical activity as both a barrier to and a motivator was a central theme across the interviews, even where it was not explicitly discussed.

\section{Ways of socialising}

Many of the women observed that most boys socialise through sport, also noting that this was not specific to Indian people:

“...there's so many similar guys who have got similar ages in Manchester so that's how they socialise, they just play football in the park. Whereas with girls it's not like there's an easy way to play a sport together" (Participant 1, Second-generation).

\section{Physical appearance}


Almost all second-generation women felt motivated to take some form of exercise by pressure to look attractive or feminine. The majority of second-generation women said they did physical activity to maintain or lose weight, while some also discussed pressures to look 'good' during physical activity in the form of people's comments on their appearance while exercising; having friends who were put off cycling because of anxieties about how they might look or mess up their hair, and feeling uncomfortably on display in the weights-area of a gym:

"we just used to get stared at... it just wasn't a nice experience" (Participant 2, Second-generation).

\section{Time for oneself}

Second-generation women spoke about exercising a means of taking time out to do something for themselves. For instance, one participant described attending yoga classes.

"...my husband goes to the gym, my kids go to the gym but I don't do anything so that was just something for me" (Participant 14, Second-generation, Bank clerk).

\section{Safety concerns}

Some second-generation women reported that their own outside play and active travel in childhood had been restricted by their parents' concerns for girls' safety: "...they'd never feel comfortable sending me out by myself, so they'd drive me everywhere really" (Participant 3, Second-generation, Medical student). Firstgeneration women who had been raised in India articulated the same concerns and consequent restrictions on outside play and active travel in childhood.

\section{Domestic activity and family priorities}

Most participants noted that girls in Indian families are expected to do more housework than boys, and that they themselves, as children, had done more housework than their brothers. The generations differed, however, regarding expectations of the wife and mother to look after the family. First-generation women described being encouraged as children by their parents to do the housework, because they would be expected to maintain the household when they married, and spoke about prioritising family care and cooking above all other activities except housework.

For the second-generation, family responsibility was less of a concern, especially for women in the 20 to 24 age group who did not have children. Among women who had children, or were married, the secondgeneration were more likely to prioritise their physical activity:

"we haven't got that burden on us that much, so we can focus on us" (Participant 20, second-generation, Works in family business).

\section{Religion}


Second-generation Hindus, Sikhs and Jains generally did not believe their religion influenced their decisions about exercise, with some exceptions. Hindu women who said their religion does influence their exercise cited yoga and 'mental exercises', but were unclear about the precise role of yoga in Hinduism. Some women discussed the role of religious clubs in encouraging physical activity, rather than the religion itself.

Muslim women cited the Koran, saying that its health messages were similar to the health messages they have heard in other media sources, commenting also that Islam influences how women exercise by prescribing modesty and non-mixing with men.

The first-generation had mixed views about whether religion influenced physical activity. Many women said their religion did not influence their activity, but our sample did not include any first-generation Muslim women. Of those who said their religion did influence physical activity, it was always either through yoga for Hindus, or through activities arranged by religious organisations.

\section{Ageing and IIIness}

The first-generation almost exclusively spoke of the need to exercise as one ages. While the majority of the younger second-generation participants were motivated to exercise for their appearance, some reported that they had also become motivated to exercise for health reasons after their parents developed health problems such as borderline diabetes and heart attacks:

"... with my dad being on the borderline [of diabetes] ...so it's all like, you don't want to get things like that" (Participant 4, Second-generation, Medical student).

\section{Schooling}

\section{Physical education (PE) lessons}

Participants who had completed all or at least part of their schooling in the UK described positive experiences of doing sports and PE in school. Women said that although they were not encouraged to exercise at home, this was sometimes because their parents believed that their daughter was getting exercise through school PE. Many second-generation women discussed the positive impact of PE at school in teaching them about the importance of physical activity. This was true even of women who described themselves as 'not sporty' or not in the school sports teams:

"I think we've learnt through school and stuff - we've been told how important exercise is and to have an active lifestyle is good for your health" (Participant 7, Second-generation, Mathematics student).

No first-generation participant reported that their school had directly addressed this issue, even if they had done sports at school.

\section{Education as a barrier to physical activity in adolescence}


Some second-generation women received more parental encouragement to study than to be active once they were in adolescence:

"... You're going to get more in life by studying than going to the gym or playing sports, so (laughs). That's the way it was when I was growing up to be honest" (Participant 6, Second-generation, Dentist).

\section{The media}

Second-generation women reported that mainstream English-language media (television, films, magazines and the news) provide a general message that activity is important, though this is usually about weight and looks, rather than physical activity for health.

The majority of first-generation participants watched Asian television channels almost exclusively, and described these channels as having no physical activity message, with the exception of yoga. The second-generation reinforced these observations this when talking about their parents:

"My dad watches Indian channels, which is where I could see it, but as I say, those channels come from India and they don't really push health as much as we do here." (Participant 4, Second-generation, Medical student).

\section{The neighbourhood}

\section{Local facilities for physical activity}

Both generations were aware of local facilities in their area, such as parks and leisure centres. Some second-generation women described using local parks to socialise in, or to run in. By contrast, almost all of the first-generation women described parks as being for children, and said they would only go there with children:

"When they were young children I used to go, but now I don't go park." (Participant 12, First-generation, Supermarket General Assistant).

Some of the second-generation also described only going to parks with children, but this attitude was not universal.

\section{Discussion}

The range of barriers to and motivators for physical activity differs for adult second-generation Indian women compared with women of the first-generation. Second-generation women's leisure-time physical activity seems to have been restricted in childhood as a result of the gender norms of their parents, who were often first-generation immigrants to the UK. However, British schooling and English-language media had a significant influence, which was largely described as having a positive effect on physical activity. As adults, these women's concerns over appearance and concerns with being 'feminine' while doing sport 
acted as barriers to physical activity, barriers that are also reported in the literature about White British women ${ }^{19}$.

The influence of gender on the second-generation women in our study is consistent with previous research about the influence of gender expectations on physical activity among young women and teenage girls in English-speaking countries (the UK, the United States, and Australia). These studies all report that women and teenage girls in these countries worry about sweating during exercise and about maintaining a 'feminine' appearance while playing sports, implying that that participating in physical activity conflicts with their ideas of feminine identity ${ }^{20-25}$. These observations resonate with comments made by participants in our study about how some women feel pressure to look good while doing physical activity, with some succumbing to this and others being active regardless. Maintenance of a 'feminine' appearance was also a motivator for some women in our study, which is line with literature exploring motivations for physical activity in the general population in the $\mathrm{UK}^{19}$.

Women in our study reported having been restricted in their outdoor activities in childhood, while also accepting and understanding these restrictions. Anwar (1998) describes findings of surveys and interviews conducted between 1975 and 1994 in Birmingham, England, that examined leisure and free time among British South Asians. Anwar notes that South Asian parents' fears about daughters having undesirable relationships with boys may have made them stricter towards daughters, and that some younger South Asians (aged below 35) accepted the difference in freedom between themselves and White people of the same age ${ }^{26}$

Some of the women in our study described how, when their parents provided no opinion on physical activity, the education they received in schools served to provide a positive one; when participants had been encouraged to be active by their parents, school education reinforced these messages. Curriculum changes during the late $20^{\text {th }}$ Century allowed for more choice of activities and encouraged activities outside of school time. In conjunction with the increase in sports and leisure provision in local areas from the 1970s onwards, these changes will have increased both the opportunity and aspiration to do physical activity ${ }^{27}$. It is likely that physical education classes, while perhaps promoting particular sports, particularly for girls ${ }^{28}$, has had an overall positive impact on the attitudes towards physical activity in the second-generation Indian women in our study.

Some women in our study reported that education was prioritised over physical activity during their childhood. Platt (2005) suggests that the high levels of achievement of second generation British Indians and African Asians may be due to their migrant parents asserting their original background through their children, by encouraging education and emphasising its importance ${ }^{29}$. Abbas (2002) interviewed parents and children of South Asians in Birmingham ${ }^{30}$ and discusses how differences in parents' social capital, knowledge and religion influence the education experiences of South Asians in Birmingham.

Our findings indicate that second-generation Indian women, while aware of stereotypical ideas about Indian society, do not adhere rigidly to conventional gender roles themselves. Some second-generation 
participants resisted any connection between their self-identification as Indian and their physical activity. Aware of stereotypical attitudes or values assigned to Indian people, or sometimes themselves describing attitudes 'typical' of their parents' generation, these women revealed in interviews that they did not share these attitudes themselves. Indeed, a minority of these women considered that there is no difference between second-generation Indian and White British women in motivations for or barriers to physical activity, dismissing as irrelevant the idea that their ethnic identity might in some way restrict or influence their physical activity or that of their generation. The women who described potential ethnicity-related social barriers to physical activity considered these to be associated with the role of women in the Indian family and in Indian society generally. Second-generation informants' rejection of traditional gender roles thus implies that, for them, their Indian ethnicity has minimal impact on their physical activities as adults.

Acknowledging the existence of attitudes or values held by many Indian people yet not applying them to one-self indicates a complex self-identity that combines elements of wider British culture and the culture inherited from their parents, which is consistent with theories of intersectionality ${ }^{15}$. On the whole, secondgeneration women rejected the gender roles taught by their parents, such as the expectation that women prioritise the home and family over themselves. They did, however, appear to have been influenced by female gender norms widely prevalent in British society, evidence by their concerns over appearance and appearing feminine while doing physical activities.

This study was unique in its aim to explore the influences on physical activity in second-generation Indian women in the UK. The use of a socio-ecological model ensured that the interviews with participants captured a wide array of influences on physical activity. A limitation of the study was the relatively low number of first-generation women included. Ideally, all first-generation participants would have been mothers of the second-generation participants, but it proved challenging to recruit both mothers and daughters into the study, with often only one agreeing to participate. The low number of first-generation women means we may not have achieved theoretical saturation in our sample; however, the emergent themes for this group concurred with those reported on in previous literature ${ }^{3}$.

\section{Conclusion}

The motivators and barriers to physical activity differ between first and second generation British Indian women. While both generations were strongly influenced by gender, influences relating to their Indian ethnicity were much more relevant for the first-generation than the second generation.

Interventions aimed at increasing physical activity among British Indian women may require targeted approaches for each generation. For the second-generation, combating negative gender influences on physical activity, continuing physical education lessons in school, and reducing the cost of physical activity classes and gyms may all positively affect physical activity. For the first-generation, family-based interventions and those using Asian media channels may be more successful. 
These factors are also likely to be applicable to second-generation UK Bangladeshi and Pakistani women. However, as these ethnic groups are also more likely to have lower incomes and live in more deprived areas, cost and local facilities could prove a more significant barrier to physical activity. Future research should explore second-generation women from other ethnic backgrounds, those on lower incomes and examine the effects of Islam and migration history on the physical activity of second-generation women.

\section{Declarations}

\section{Ethics approval and consent to participate}

We received ethics approval from the University of Oxford Research Ethics Committee (reference number MSD-IDREC-C1-2012-96). All participants consented to participate in the research.

\section{Consent for publication}

All participants in the study consented to having their words quoted in research outputs.

\section{Availability of data and materials}

The datasets generated and analysed during the current study are not publicly available due to the fact that they contain potentially identifiable information, but are available from the corresponding author on reasonable request.

\section{Competing interests}

The authors declare that they have no competing interests

\section{Funding}

This study was funded by the British Heart Foundation, which had no role in the design of the study, collection, analysis or interpretation of the data or in the writing of the manuscript.

\section{Authors' contributions}

PB conducted and analysed the interviews and drafted the manuscript. AS and CF contributed to the design of the study and edited the manuscript. All authors read and approved the final manuscript.

\section{Acknowledgements}

The authors would like to acknowledge all the participants in this study for providing their time and data.

\section{References}

1. Lee I-M, Shiroma EJ, Lobelo F, Puska P, Blair SN, Katzmarzyk PT. Effect of physical inactivity on major non-communicable diseases worldwide: an analysis of burden of disease and life expectancy. 
The Lancet. 2017;380(9838):219-229. doi:10.1016/S0140-6736(12)61031-9

2. Ranasinghe CD, Ranasinghe P, Jayawardena R, Misra A. Physical activity patterns among SouthAsian adults: a systematic review. The International Journal of Behavioural Nutrition and Physical Activity. 2013;10(1):116. doi:10.1186/1479-5868-10-116

3. Babakus WS, Thompson JL. Physical activity among South Asian women: a systematic, mixedmethods review. The International Journal of Behavioural Nutrition and Physical Activity. 2012;9(1):150. doi:10.1186/1479-5868-9-150

4. Williams ED, Stamatakis E, Chandola T, Hamer M. Assessment of physical activity levels in South Asians in the UK: findings from the Health Survey for England. Journal of epidemiology and community health. 2011;65(6):517-521. doi:http://dx.doi.org/10.1136/jech.2009.102509

5. Bhatnagar P, Shaw A, Foster C. Generational differences in the physical activity of UK South Asians: a systematic review. The international journal of behavioral nutrition and physical activity. 2015;12(1):96. doi:10.1186/s12966-015-0255-8

6. Office for National Statistics. 2011 Census: Aggregate Data (England and Wales).; 2011.

7. Hosper K, Nicolaou M, van Valkengoed I, Nierkens V, Stronks K. Social and cultural factors underlying generational differences in overweight: a cross-sectional study among ethnic minorities in the Netherlands. BMC Public Health. 2011;11(1):105.

8. Hosper K, Nierkens V, Nicolaou M, Stronks K. Behavioural risk factors in two generations of nonWestern migrants: do trends converge towards the host population? Eur J Epidemiol. 2007;22:163172.

9. Thomson MD, Hoffman-Goetz L. Defining and measuring acculturation: A systematic review of public health studies with Hispanic populations in the United States. Social Science \& Medicine. 2009;69(7):983-991.

10. Abraido-Lanza AF, Armbrister AN, Florez KR, Aguirre AN. Toward a Theory-Driven Model of Acculturation in Public Health Research. Am J Public Health. 2006;96(8):1342-1346. doi:10.2105/ajph.2005.064980

11. Markus HR, Kitayama S. Culture and the self: Implications for cognition, emotion, and motivation. Psychological Review. 1991;98(2):224-253.

12. Chadda RK, Deb KS. Indian family systems, collectivistic society and psychotherapy. Indian journal of psychiatry. 2013;55(Suppl 2):S299-309. doi:10.4103/0019-5545.105555

13. Henderson CE. Culture and Customs of India. Westport: Greenwood Publishing Group; 2002.

14. Sallis JF, Cervero RB, Ascher W, Henderson KA, Kraft MK, Kerr J. An ecological approach to creating active living communities. Annual review of public health. 2006;27:297-322. doi:10.1146/annurev.publhealth.27.021405.102100

15. Hancock A-M. When Multiplication Doesn't Equal Quick Addition: Examining Intersectionality as a Research Paradigm. Perspectives on Politics. 2007;5(01):63-79. doi:10.1017/S1537592707070065 
16. Guruge S, Khanlou N. Intersectionalities of influence: researching the health of immigrant and refugee women. Can J Nurs Res. 2004;36(3):32-47.

17. Smith NR, Kelly YJ, Nazroo JY. The effects of acculturation on obesity rates in ethnic minorities in England: evidence from the Health Survey for England. The European Journal of Public Health. 2011. doi:10.1093/eurpub/ckr070

18. Department for Communities and Local Government. English Indices of Deprivation 2010. London; 2011.

19. Allender S, Cowburn G, Foster C. Understanding participation in sport and physical activity amongst children and adults: a review of qualitative studies. Health Education Research. 2006;21(6):826-835.

20. Whitehead S, Biddle S. Adolescent girls' perceptions of physical activity: A focus group study. European Physical Education Review. 2008;14(2):243-262. doi:10.1177/1356336X08090708

21. Azzarito L, Solmon MA, Harrison L. "...If I Had a Choice, I Would...." A Feminist Poststructuralist Perspective on Girls in Physical Education. Research Quarterly for Exercise and Sport. 2006;77(2):222-239. doi:10.1080/02701367.2006.10599356

22. Cockburn C, Clarke G. "Everybody's looking at you!": Girls negotiating the "femininity deficit" they incur in physical education. Women's Studies International Forum. 2002;25(6):651-665. doi:10.1016/S0277-5395(02)00351-5

23. Coleman L, Cox L, Roker D. Girls and young women's participation in physical activity: psychological and social influences. Health Education Research. 2008;23(4):633-647. doi:10.1093/her/cym040

24. Slater A, Tiggemann M. "Uncool to do sport": A focus group study of adolescent girls' reasons for withdrawing from physical activity. Psychology of Sport and Exercise. 2010;11(6):619-626. doi:10.1016/j.psychsport.2010.07.006

25. Choi PYL. Femininity and the Physically Active Woman. Philadelphia: Taylor \& Francis; 2000.

26. Anwar M. Between Cultures: Continuity and Change in the Lives of Young Asians. London: Routledge; 1998.

27. Green K, Smith A, Roberts K. Young people and lifelong participation in sport and physical activity: a sociological perspective on contemporary physical education programmes in England and Wales. Leisure Studies. 2005;24(1):27-43. doi:10.1080/0261436042000231637

28. Smith A, Green K, Thurston M. 'Activity choice' and physical education in England and Wales. Sport, Education and Society. 2009;14(2):203-222. doi:10.1080/13573320902809096

29. Platt L. Migration and Social Mobility: The Life Chances of Britain's Minority Ethnic Communities. York: Joseph Rowntree Foundation; 2005.

30. Abbas T. The Home and the School in the Educational Achievements of South Asians. Race Ethnicity and Education. 2002;5(3):291-316. doi:10.1080/1361332022000004878 